\title{
Teledermatology in the Control of Skin Neglected Tropical Diseases: A Systematic Review
}

\author{
Tejas P. Joshi', Vicky Ren ${ }^{2}$
}

1 School of Medicine, Baylor College of Medicine

2 Department of Dermatology, Baylor College of Medicine

Key words: global dermatology, global health, skin neglected tropical diseases, teledermatology, telemedicine

Citation: Joshi TP, Ren V. Teledermatology in the control of skin neglected tropical diseases: a systematic review. Dermatol Pract Concept. 2021; 11(4): e2021130. DOI: https://doi.org/10.5826/dpc.1104a130

Accepted: April 25, 2021; Published: September 2021

Copyright: $\odot 2021$ Joshi and Ren. This is an open-access article distributed under the terms of the Creative Commons Attribution License BY-NC-4.0, which permits unrestricted noncommercial use, distribution, and reproduction in any medium, provided the original authors and source are credited

Funding: None.

Competing interests: None.

Authorship: Both authors have contributed significantly to this publication.

Corresponding author: Tejas P. Joshi, BS, School of Medicine, Baylor College of Medicine, One Baylor Plaza Houston, TX, USA.

E-mail: tejas.joshi@bcm.edu

\footnotetext{
ABSTRACT Introduction: Neglected tropical diseases (NTDs) include a group of about 20 illnesses that have garnered relatively little attention, despite their ability to inflict significant suffering and disability. Skin neglected tropical diseases (sNTDs) are a subset of NTDs that present with cutaneous manifestations and are well known for their ability to generate stigma and promote poverty. Teledermatology (TD) represents a potential method to control sNTDs.

Objective: We sought to analyze the potential for TD to ease the burden of sNTDs.

Methods: We performed a systematic literature search using the Texas Medical Center Library One Search, which scans 167 databases, including Embase, PubMed, and Scopus. We included all original investigations published after 2011 that assessed the impact of TD intervention in the control of one or more sNTDs. We excluded studies not written in English and studies that did not perform any outcome analyses.

Results: Twenty studies met our search criteria, and 18 expressed positive attitudes towards TD. Overall, we found that TD may be a sustainable, cost-effective strategy for expanding access to care for individuals afflicted with sNTDs. However, poor image quality, lack of access to further diagnostic tests, and ethical, legal, and cultural issues pose as barriers to TD utilization.

Conclusion: TD may be helpful in achieving control of sNTDs but has its limitations. An integrated approach, which employs TD in conjunction with other strategies, represents a realistic path for alleviating sNTDs.
} 


\section{Introduction}

Neglected tropical diseases (NTDs) include about 20 debilitating illnesses that affect the world's most indigent, engendering disability, and suffering [1]. As opposed to HIV/AIDS, tuberculosis, and malaria, NTDs have garnered relatively little attention and funding [2]. Nonetheless, the burden of NTDs is significant, with approximately 1 billion people afflicted, resulting in a loss of roughly 26 million disability-adjusted life-years [3]. Skin neglected tropical diseases (sNTDs) constitute a subset of NTDs that present with cutaneous manifestations. As identified by the World Health Organization (WHO), they include Buruli ulcer (BU), cutaneous leishmaniasis (CL), fungal diseases, leprosy, lymphatic filariasis (LF), mycetoma, onchocerciasis, post-kala-azar dermal leishmaniasis, scabies, and yaws [4]. sNTDs are particularly stigmatizing and lead to marginalization of afflicted individuals, trapping them in a vicious cycle of poverty and disease progression [5].

Teledermatology (TD) may be a powerful tool in facilitating the eradication of sNTDs. In the highly visual field of dermatology, TD has been touted as a cost-effective, time-efficient option for care delivery. Moreover, TD offers 2 flexible models of care: synchronously, over a videoconferencing platform and asynchronously, through photographs sent via online communication tools (store and forward dermatology) [6]. Both synchronous and asynchronous TD models have been extensively deployed during the coronavirus disease 2019 (COVID-19) pandemic, and despite their deficiencies, represent promising paradigms of delivering remote care [7]. As the post-pandemic utilization of TD will likely grow, it is important to consider how TD can aid in the management of sNTDs; simultaneously, it is worth keeping in mind the limitations of TD.

\section{Objectives}

Considering the potential for TD in the management of sNTDs, we reviewed the literature for cases in which TD was used to manage sNTDs. When possible, we extracted information regarding patient and physician satisfaction with TD, time to receiving a TD diagnosis, concordance between TD and face-to-face (FTF) diagnoses, clinical outcomes, cost of TD consultation, encryption of TD platform used, and adequacy of images submitted.

\section{Methods}

We performed a literature search using the Texas Medical Center Library One Search, which scans 167 databases, including Embase, PubMed, and Scopus. We performed our search on February 27, 2021, using the search criteria "teledermatology" AND "skin neglected tropical disease." For thoroughness, we performed cross validation with every sNTD listed by the WHO, inputting the search criteria "teledermatology" AND "[sNTD recognized by the WHO]." We limited our search to articles published in 2011 or later. Eligible studies were original investigations in which a TD intervention was implemented to diagnose and/or manage one or more sNTDs. We excluded commentaries, editorials, and reviews that did not present any original data. We also excluded case reports (although we discuss some anecdotally to illustrate proof of concept). Articles not written in English and articles that presented TD along with other interventions (such that the impact of TD alone could not be isolated) were also excluded from analysis. Lastly, we excluded articles that implemented TD in the diagnosis of sNTDs but did not perform any further analyses (eg, concordance measures, clinical improvement, time to diagnosis, etc.).

In preparing this systematic review, we adhered to the Preferred Reporting Items for Systematic Reviews and Meta-Analyses (PRISMA) guidelines. We include a PRISMA flow diagram that illustrates our search (Figure 1).

\section{Results}

Twenty studies met our search criteria (Table 1). Fungal infections were the most common sNTDs to be targeted by TD, being described in 18/20 studies analyzed. Scabies (10/20), CL (5/20), and leprosy (5/20) were the next most common sNTDs to be diagnosed by TD. We did not find any eligible studie that utilized TD in diagnosing mycetoma, onchocerciasis, post-kala-azar dermal leishmaniasis, or yaws. The studies we reviewed had a wide geographical distribution: Latin America (6/20), Africa (7/20), the Middle East (4/20), and Asia (3/20). Interestingly, we also found one study by Hwang et al evaluating TD use in the United States military in deployed settings: while the majority of TD consults were requested from Iraq and Afghanistan, almost 50 locations utilizing TD appointments were described [8]. The majority of the studies we reviewed (18/20) adopted a generally favorable outlook towards TD. Additionally, 5 studies assessed the concordance between FTF and TD consultations, and the agreement ranged from $56 \%$ [9] to $95 \%$ [10]; the study reporting $56 \%$ agreement did not consider this degree of concordance to be sufficient to recommend the independent use of TD [9].

We recognize selection bias as a potential weakness of all the studies we reviewed, as patients uncomfortable with TD would not have elected to participate. Only 3/20 studies documented the number of individuals who declined to participate. 

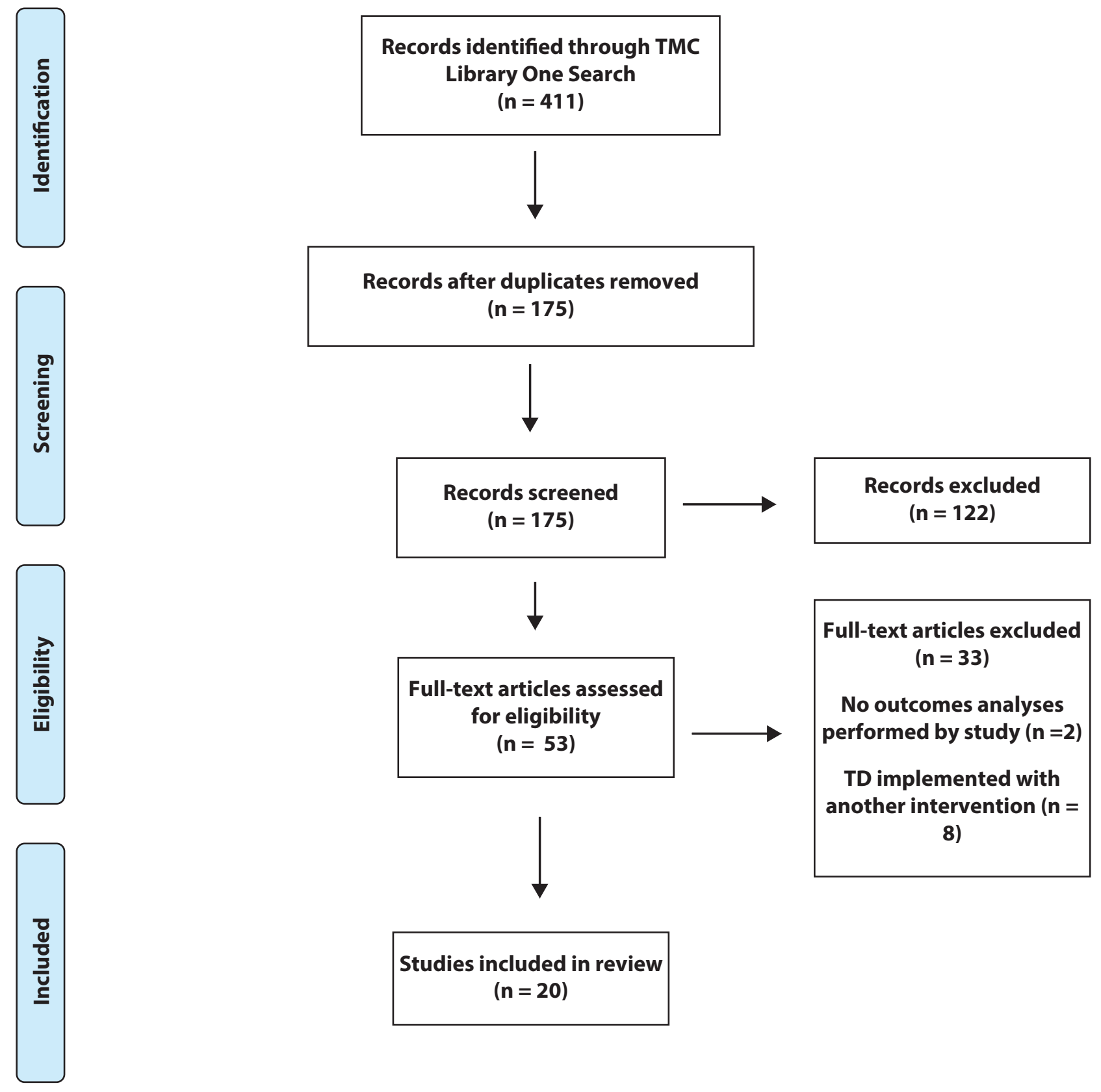

Figure 1. PRISMA Flow Diagram Illustrating the Methodology Informing Our Search.

$\mathrm{TD}=$ teledermatology $\mathrm{TMC}=$ Texas Medical Center

\section{Teledermatology: Advantages and Promises}

Expansion of dermatologic care to underserved regions plagued by sNTDs represents perhaps the most significant benefit of TD. While there is no study that assesses the number of dermatologists per capita by country, data from the United States alone is concerning for sharp disparities between dermatologic care in rural and urban centers, with the difference in dermatologist density between metropolitan and rural counties exceeding 4 dermatologists per 100,000 people [28]. It is likely that such disparities are more pronounced in developing regions where sNTDs constitute a major burden of disease. The studies we reviewed indicate the potential for TD to bridge this gap in access to care, as 12/20 were conducted in rural locations and all were conducted in resource limited settings. Case reports from Nepal support the potential for TD to penetrate rural areas and address sNTDs such as CL [29] and tinea incognito [30]. Formation of a global network of teledermatologists may facilitate the eradication of sNTDs in regions where in-person care may not be feasible.

Additionally, the remote aspect of TD provides an opportunity to practice global health sustainably and allows for continuity of care. Moreover, it may have an educational value: with the patients' consent, medical students and residents can also participate in TD consults, gaining exposure to sNTDs and global health without having to travel. Importantly, TD can also help general practitioners (GPs) recognize 
Table 1. Literature Assessing TD Intervention in sNTD Control

\begin{tabular}{|c|c|c|c|c|c|}
\hline Reference & $\begin{array}{l}\text { Country/ } \\
\text { Region }\end{array}$ & SNTD & $\begin{array}{l}\text { Location of } \\
\text { Consulting } \\
\text { Dermatologist }\end{array}$ & $\begin{array}{l}\text { Study } \\
\text { Size }\end{array}$ & Major Finding(s) \\
\hline Baze, 2011 [11] & Honduras & FI, scabies & Foreign location & 105 & $\begin{array}{l}\text { 91\% patient satisfaction; high } \\
\text { dermatologist satisfaction; } 4.3 / 5 \text { image } \\
\text { quality }\end{array}$ \\
\hline $\begin{array}{l}\text { Garcia-Romero et } \\
\text { al, 2011[12] }\end{array}$ & Mexico & Scabies & Local jurisdiction & 44 & $\begin{array}{l}75 \% \text { clinical improvement following TD } \\
\text { consult }\end{array}$ \\
\hline $\begin{array}{l}\text { Tsang \& Kovarik, } \\
2011[13]\end{array}$ & $\begin{array}{l}\text { Sub-Saharan } \\
\text { Africa }\end{array}$ & Leprosy, LF, FI & Foreign location & 55 & $\begin{array}{l}58 \% \text { correlation between TD and } \\
\text { pathological analysis }\end{array}$ \\
\hline \begin{tabular}{|l} 
Oseit-tutu et al, \\
$2013[14]$
\end{tabular} & Ghana & FI & Local jurisdiction & 34 & $\begin{array}{l}79 \% \text { concordance between FTF and TD } \\
\text { consults }\end{array}$ \\
\hline \begin{tabular}{|l} 
Montazeri et al, \\
$2013[15]$
\end{tabular} & Iran & CL, FI & Local jurisdiction & 91 & $\begin{array}{l}85 \% \text { concordance between FTF and TD } \\
\text { consults }\end{array}$ \\
\hline $\begin{array}{l}\text { Smith et al, } 2013 \\
{[16]}\end{array}$ & Kenya & FI & Local jurisdiction & 32 & $\begin{array}{l}\text { Mean sensitivity of } 73 \% \text { and specificity } \\
\text { of } 83 \% \text { for diagnosing tinea infections } \\
\text { via TD }\end{array}$ \\
\hline $\begin{array}{l}\text { Kaliyadan et al, } \\
2013[10]\end{array}$ & Saudi Arabia & FI & Local jurisdiction & 166 & $\begin{array}{l}95 \% \text { concordance between FTF and TD } \\
\text { consults }\end{array}$ \\
\hline $\begin{array}{l}\text { Greisman et al, } \\
2014[17] \\
\end{array}$ & $\begin{array}{l}\text { Guatemala } \\
\text { and Uganda }\end{array}$ & $\begin{array}{l}\text { BU, CL, FI, LF, } \\
\text { scabies }\end{array}$ & Foreign location & 93 & $\begin{array}{l}\text { TD rectified GP diagnoses in } 56 \% \text { of } \\
\text { cases }\end{array}$ \\
\hline $\begin{array}{l}\text { Hwang et al, } 2014 \\
{[8]}\end{array}$ & $\begin{array}{l}\text { U.S. Military } \\
\text { Facilities }\end{array}$ & $\begin{array}{l}\text { BU, CL, scabies, } \\
\text { FI }\end{array}$ & Foreign location & 658 & $\begin{array}{l}98 \% \text { of consults answered in } 24 \\
\text { hours; } 46 \text { evacuations avoided and } 41 \\
\text { evacuations facilitated due to TD consult }\end{array}$ \\
\hline $\begin{array}{l}\text { Lipoff et al, } 2015 \\
{[18]}\end{array}$ & $\begin{array}{l}\text { Sub-Saharan } \\
\text { Africa }\end{array}$ & FI & Foreign location & 1229 & $\begin{array}{l}60 \% \text { concordance between dermatologist } \\
\text { and clinicians submitting images }\end{array}$ \\
\hline Patro et al, 2015 [9] & India & FI, scabies & Local jurisdiction & 206 & $\begin{array}{l}56 \% \text { concordance between FTF visit } \\
\text { conducted by GP and TD }\end{array}$ \\
\hline $\begin{array}{l}\text { Nguygen et al, } 2017 \\
{[19]}\end{array}$ & Cameroon & FI, leprosy, LF & Foreign location & 145 & $\begin{array}{l}\text { Acceptable concordance between } \\
\text { diagnosis as made by TD and light } \\
\text { microscopy }\end{array}$ \\
\hline \begin{tabular}{|l} 
Saleh et al, 2017 \\
{$[20]$}
\end{tabular} & Egypt & FI & Local jurisdiction & 600 & $\begin{array}{l}87 \% \text { concordance between FTF and TD } \\
\text { consults }\end{array}$ \\
\hline $\begin{array}{l}\text { Ismail et al, } 2018 \\
{[21]}\end{array}$ & Afghanistan & CL, FI, scabies & Local jurisdiction & 326 & $\begin{array}{l}\text { Images of sufficient quality to render } \\
\text { diagnoses in } 94 \% \text { of consults }\end{array}$ \\
\hline Faye et al, 2018 [22] & Mali & $\begin{array}{l}\text { FI, leprosy, } \\
\text { scabies }\end{array}$ & Local jurisdiction & 180 & $\begin{array}{l}96 \% \text { of patients properly managed via } \\
\text { TD; mean time to dermatologist response } \\
\text { was } 32 \text { hours }\end{array}$ \\
\hline $\begin{array}{l}\text { Messagier et al, } \\
2019[23]\end{array}$ & $\begin{array}{l}\text { French } \\
\text { Guiana }\end{array}$ & $\begin{array}{l}\text { CL, FI, leprosy, } \\
\text { scabies }\end{array}$ & Local jurisdiction & 254 & $\begin{array}{l}85 \% \text { satisfaction from users; } 92 \% \text { were } \\
\text { able to be managed in peripheral health } \\
\text { centers }\end{array}$ \\
\hline $\begin{array}{l}\text { Cutler et al, } 2019 \\
{[24]}\end{array}$ & Haiti & FI, scabies & Foreign location & 101 & $\begin{array}{l}\text { Average time from intake to case closure } \\
\text { was } 1.67 \text { days; average diagnostic } \\
\text { concordance between Haitian providers } \\
\text { and U.S. dermatologists was } 69 \%\end{array}$ \\
\hline $\begin{array}{l}\text { Malmontent et al, } \\
2020[25]\end{array}$ & $\begin{array}{l}\text { French } \\
\text { Guiana } \\
\end{array}$ & Leprosy & Local jurisdiction & $52 *$ & TD used to solve four cases of leprosy \\
\hline $\begin{array}{l}\text { Singhal et al, } 2020 \\
{[26]}\end{array}$ & India & FI; scabies & Local jurisdiction & 520 & $\begin{array}{l}9 \% \text { of patients could not be assessed } \\
\text { due to poor image quality; poor patient } \\
\text { compliance to treatment following TD } \\
\text { consult also noted }\end{array}$ \\
\hline Lee et al, 2021 [27] & Taiwan & FI; scabies & Local jurisdiction & 426 & $\begin{array}{l}\text { Subjective patient improvement }>75 \% \\
\text { year-round and case closure rate }>85 \% \\
\text { year-round }\end{array}$ \\
\hline
\end{tabular}

$\mathrm{BU}=$ Buruli ulcer; $\mathrm{CL}=$ cutaneous leishmaniasis; $\mathrm{FI}=$ fungal infections; $\mathrm{FTF}=$ face to face; $\mathrm{GP}=$ general practitioner; $\mathrm{LF}=$ lymphatic filariasis; sNTD=skin neglected tropical diseases; TD=teledermatology.

While the total number of cases for this study was 639 , TD was used in only 52 cases. 
lesions associated with sNTDs endemic to the region where they practice. Such an application of TD was successfully applied in the United Kingdom [31].

The cost savings of TD should also be considered. Among the evaluated studies, 3 evaluated the financial aspect of TD implementation: Greisman et al reported TD in Guatemala and Uganda to be entirely feasible from a financial standpoint [17]; Cutler et al reported the cost of managing a TD platform in Haiti to be only US\$5 per month [24]; and Messagier et al reported that TD mitigated healthcare expenses for more than $50 \%$ of patients in French Guiana [23]. As sNTDs affect the world's most indigent, cost represents a significant barrier to care. TD may be a cost-effective way to expand care to individuals suffering from sNTDs.

Another advantage of TD is that it can be leveraged with mobile applications and artificial intelligence (AI). Although none of the studies we reviewed employed mobile applications and $\mathrm{AI}$ in conjunction with $\mathrm{TD}$, we acknowledge the potential synergy of combining these technologies. Recently, Carrion et al reviewed the utility of mobile applications in mitigating the burden of sNTDs and although they concluded that numerous barriers to widespread mobile health implementation remain, their review demonstrates that creative mobile technologies, some with a modicum of success, do exist and can help curb the morbidity associated with sNTDs [32]. Adding AI can further potentiate the power of TD. A study conducted in the Philippines by Velasco et al showed that a neural network was able to diagnose common skin conditions with up to $94 \%$ accuracy [33]. Altogether, the combination of TD, mobile technologies, and AI represents a potent technological triad that may be used to control sNTDs.

The applications of TD in managing sNTDs that arise in non-community settings should also be acknowledged. While $19 / 20$ studies we reviewed apply TD in the management of sNTDs in local community settings, the study by Hwang et al shows that TD can be effectively utilized to manage sNTDs that arise in military deployments [8]. TD also has the potential to be used in the management of sNTDs in refugee situations, and such an application of TD has been suggested in the treatment of skin disease in the refugee population in Europe [34] and the Rohingya in Bangladesh [35]. Furthermore, TD has the potential to diagnose non-endemic cases of sNTDs. In an increasingly interconnected world affected by rising global temperatures, the potential of sNTDs to present in regions outside the tropics has become a valid concern. In 2018, Hotez summarized how recent changes in climate, globalization, and urbanization have spurred the surge of NTDs in Texas [36]. Under these new circumstances, TD may acquire a truly global scope in the management of sNTDs; for example, in 2019 a woman who had recently immigrated to the United States from Brazil was diagnosed with leprosy using TD [37].

\section{Teledermatology and its Limitations}

Inadequate image quality represents a major concern for TD. Six of the 20 studies we reviewed identified poor image quality as a barrier to diagnosis. Furthermore, TD works mostly as a triage system, and while it has the ability to identify patients that promptly need dermatologic attention, additional diagnostic procedures, such as biopsies, potassium hydroxide $(\mathrm{KOH})$ preparations, dermoscopy, microscopy, and analysis under Wood's lamp must all be sacrificed in an entirely TD model of care. In 10/20 studies, further diagnostic evaluation was recommended following a TD consult, and 2/20 studies indicated a lack of access to further diagnostic procedures. Many sNTDs may present ambiguously, necessitating further evaluation: microscopy for Buruli ulcer, cutaneous leishmaniasis, and lymphatic filariasis; biopsy for leprosy; and $\mathrm{KOH}$ preparations for fungal infections [38]. In developing countries where sNTDs are endemic and resources are scarce, further studies may not be possible. In such cases, a TD consult could potentially cause more harm than good by leaving the patient in a state of anxiety and uncertainty. Furthermore, only 4/20 studies mentioned any kind of patient follow-up; thus, the long-term efficacy of TD remains unknown.

Additionally, in 7/20 studies, the consulting dermatologist was located in a foreign location. As opposed to local dermatologists, dermatologists in more remote locations may not have a nuanced understanding of local disease epidemiology and available diagnostic techniques and treatments. This lack of knowledge could lead not just to potentially incorrect diagnoses but also recommendation of unavailable treatments.

The ethico-legal aspects of TD implementation must also be considered. Patient privacy represents a valid concern for TD implementation. Impressively, 14/20 studies acknowledged the issue of encryption and made an attempt at preserving patient confidentiality. The studies we reviewed utilized a myriad of platforms to perform TD consults, including Facebook [12], WhatsApp [26], Dropbox [20], and Tango [10], but the encryption underlying these platforms remains unclear. In fact, WhatsApp has been deemed inappropriate for telemedicine due to concerns about privacy breaches [39]. As TD use has increased during the COVID-19 pandemic, WhatsApp has come under further scrutiny. Brunasso and Massone point out that WhatsApp is not compliant with the European Union's General Data Protection Regulation and that caution must be exercised in utilizing TD platforms [40]. Ensuring confidentiality is important, as individuals afflicted with sNTDs comprise a particularly vulnerable population and may be unable to advocate for themselves. Legal barriers to TD implementation also exist globally and are more pronounced in developing countries. Cutler et al addressed these limitations in their study on TD implementation in 
Haiti, citing that the legal framework surrounding telemedicine licensure and malpractice is nascent [24]. The control of sNTDs through TD must not come at the expense of ethical and legal transgressions.

Finally, cultural barriers to widespread TD utilization exist. From Saudi Arabia, Kaliyadan et al reported that 14\% of patients refused to have their skin photographed, citing religious and social reasons [10]. While none of the other studies we reviewed evaluate the cultural barriers to TD implementation, it is possible that the hesitancy towards TD use exists in other countries afflicted by sNTDs, many of which embrace conservative cultures. Moreover, this cultural hesitancy towards TD acceptance may be amplified when the encryption of TD platforms is tenuous. Thus, the cultural milieu limiting TD use must not be overlooked.

\section{Teledermatology: One Piece of the Puzzle}

The tremendous potential for TD is tempered by its limitations; alone, it is unlikely to eliminate sNTDs. Mass drug administration [41], advocacy, policy changes, involvement of key stakeholders, and greater investment in research have all been cited as elements essential to the control of sNTDs [42]. The community dermatology program in Guerrero, Mexico serves as an example of this integrated approach to managing sNTDs: TD is combined with education, mobilization of healthcare personnel, and involvement of local and international institutions to mitigate the burden of mycetoma [43]. Therefore, a more realistic picture of sNTD control is one where TD occupies one piece of the puzzle of sNTD eradication.

\section{Review Limitations}

As we only considered published journal articles in our literature search, we recognize publication bias is a limitation to our review. Furthermore, only the sNTDs articulated by the WHO were used in our search criteria; however, other NTDs also present with cutaneous manifestations that can be evaluated by dermatologists. For instance, reactivated Chagas disease may present as cellulitic plaques, ulcers, necrotic eschars, and panniculitis [44]. Thus, our review may not exhaustively capture the application of TD in the management of all sNTDs.

\section{Conclusion}

sNTDs represent a group of stigmatizing, poverty promoting diseases that can be effectively targeted by TD. TD can blunt the burden of sNTDs by expanding access to care in a manner that is both sustainable and cost-efficient. TD can also be deployed in combination with mobile health strategies and $\mathrm{AI}$ and used in non-community settings. However, poor image quality and the need for further diagnostic tests exemplify the limitations of the TD platform in the management of sNTDs. Ethico-legal and socio-cultural elements also constitute roadblocks to the global acceptance of TD. TD should feature as a major, but not the only, component in the strategy to eradicate sNTDs.

\section{References}

1. Hotez PJ, Aksoy S, Brindley PJ, Kamhawi S. What constitutes a neglected tropical disease? PLoS Negl Trop Dis. 2020;14(1):e0008001-e0008001. DOI:10.1371/journal. pntd.0008001. PMID: 31999732.

2. Hotez PJ. NTDs V.2.0: "blue marble health"--neglected tropical disease control and elimination in a shifting health policy landscape. PLoS Negl Trop Dis. 2013;7(11):e2570-e2570. DOI:10.1371/journal.pntd.0002570. PMID: 24278496.

3. Hotez P, Alvarado M, Basáñez M-G, et al. The Global Burden of Disease Study 2010: Interpretation and Implications for the Neglected Tropical Diseases. PLoS Negl Trop Dis. 2014;8(7):e2865-e2865. DOI:10.1371/journal.pntd.0002865. PMID: 25058013 .

4. WHO I Skin NTDs. WHO. Accessed March 3, 2021. http://www. who.int/neglected_diseases/skin-ntds/en/

5. Hay RJ, Asledu, K. Skin-Related Neglected Tropical Diseases (Skin-NTDs)_A New Challenge. MDPI - Multidisciplinary Digital Publishing Institute; 2019.DOI: 10.3390/tropicalmed4010004. PMID: 30585179.

6. Lee JJ, English III JC. Teledermatology: A Review and Update. Am J Clin Dermatol. 2018;19(2):253-260. DOI:10.1007/s40257-0170317-6. PMID: 28871562.

7. Farr, M.A., Duvic, M. \& Joshi, T.P. Teledermatology During COVID-19: An Updated Review. Am J Clin Dermatol (2021). DOI: 10.1007/s40257-021-00601-y. PMID: 33835345.

8. Hwang JS, Lappan CM, Sperling LC, Meyerle JH. Utilization of telemedicine in the U.S. military in a deployed setting. Mil Med. 2014;179(11):1347-1353. DOI:10.7205/MILMED-D-14-00115. PMID: 25373065.

9. Patro BK, Tripathy JP, De D, Sinha S, Singh A, Kanwar AJ. Diagnostic agreement between a primary care physician and a teledermatologist for common dermatological conditions in North India. Indian Dermatol Online J. 2015;6(1):21-26. DOI:10.4103/22295178.148927. PMID: 25657912.

10. Kaliyadan F, Amin TT, Kuruvilla J, Ali WHAB. Mobile teledermatology - patient satisfaction, diagnostic and management concordance, and factors affecting patient refusal to participate in Saudi Arabia. J Telemed Telecare. 2013;19(6):315-319. DOI:10.1177/1357633X13501778. PMID: 24163295.

11. Baze MR. Application and Evaluation of Teledermatology In An Underserved Area of Honduras. Published online August 2, 2011. Accessed March 3, 2021. https://vtechworks.lib.vt.edu/ handle/10919/28524

12. Garcia-Romero MT, Prado F, Dominguez-Cherit J, Hojyo-Tomomka MT, Arenas R. Teledermatology via a Social Networking Web Site: A Pilot Study Between a General Hospital and a Rural Clinic. Telemed J E Health. 2011;17(8):652-655. DOI:10.1089/ tmj.2011.0038.PMID: 21790270.

13. Tsang MW, Kovarik CL. The role of dermatopathology in conjunction with teledermatology in resource-limited settings: lessons from the African Teledermatology Project: Role of dermatopa- 
thology in conjunction with teledermatology in resource-limited settings. Int J Dermatol. 2011;50(2):150-156. DOI:10.1111/ j.1365-4632.2010.04790.x. PMID: 21244377.

14. Osei-tutu A, Shih T, Rosen A, et al. Mobile teledermatology in Ghana: Sending and answering consults via mobile platform. J Am Acad Dermatol. 2013;69(2):e90-e91. DOI:10.1016/j. jaad.2012.08.008. PMID: 23866892.

15. Montazeri, Mahideh et al. Comparison of the Accuracy of Digital Image-based and Patient Visit-based Diagnoses in an Iranian Dermatology Clinic. 2013;3(11):28-33.

16. Smith SE, Ludwig JT, Chinchilli VM, Mehta K, Stoute JA. Use of Telemedicine to Diagnose Tinea in Kenyan Schoolchildren. Telemed J E Health. 2013;19(3):166-168. DOI:10.1089/ tmj.2012.0085. PMID: 23356383.

17. Greisman L, Nguyen TM, Mann RE, et al. Feasibility and cost of a medical student proxy-based mobile teledermatology consult service with Kisoro, Uganda, and Lake Atitlán, Guatemala. Int J Dermatol. 2015;54(6):685-692. DOI:10.1111/ijd.12708. PMID: 25558031.

18. Lipoff JB, Cobos G, Kaddu S, Kovarik CL. The Africa Teledermatology Project: A retrospective case review of 1229 consultations from sub-Saharan Africa. J Am Acad Dermatol. 2015;72(6):1084 1085. DOI:10.1016/j.jaad.2015.02.1119. PMID: 25981007.

19. Nguyen A, Tran D, Uemura M, Bardin RL, Shitabata PK. Practical and Sustainable Teledermatology and Teledermatopathology: Specialty Care in Cameroon Africa. J Clin Aesthetic Dermatol. 2017;10(1):47-56.

20. Saleh N, Abdel Hay R, Hegazy R, Hussein M, Gomaa D. Can teledermatology be a useful diagnostic tool in dermatology practice in remote areas? An Egyptian experience with 600 patients. J Telemed Telecare. 2017;23(2):233-238. DOI:10.1177/1357633X16633944. PMID: 26940796.

21. Ismail A, Stoff BK, McMichael JR. Store-and-forward teledermatology service for primary care providers in Afghanistan. Int J Dermatol. 2018;57(11):e145-e147. DOI:10.1111/ijd.14165. PMID: 30070355.

22. Faye O, Bagayoko CO, Dicko A, et al. A Teledermatology Pilot Programme for the Management of Skin Diseases in Primary Health Care Centres: Experiences from a Resource-Limited Country (Mali, West Africa). Trop Med Infect Dis. 2018;3(3):88-. DOI:10.3390/tropicalmed3030088. PMID: 30274484.

23. Messagier A-L, Blaizot R, Couppié P, Delaigue S. Teledermatology Use in Remote Areas of French Guiana: Experience From a Long-Running System. Front Public Health. 2019;7:387-387. DOI:10.3389/fpubh.2019.00387. PMID: 31921751.

24. Cutler L, Ross K, Withers M, Chiu M, Cutler D. Teledermatology: Meeting the Need for Specialized Care in Rural Haiti. J Health Care Poor Underserved. 2019;30(4):1394-1406. DOI:10.1353/ hpu.2019.0097. PMID: 31680104.

25. Malmontet T, Guarmit B, Gaillet M, et al. Spectrum of skin diseases in Amerindian villages of the Upper Oyapock, French Guiana. Int J Dermatol. 2020;59(5):599-605. DOI:10.1111/ijd.14848. PMID: 32227343.

26. Singhal R, Talati K, Gandhi B, Shinde M, Nair P, Phatak A. Prevalence and pattern of skin diseases in tribal villages of $\mathrm{Gu}$ jarat: A teledermatology approach. Indian J Community Med. 2020;45(2):199-203. DOI:10.4103/ijcm.IJCM_76_19. PMID: 32905082 .

27. Lee C-H, Huang C-C, Huang J-T, et al. Live-interactive teledermatology program in Taiwan: One-year experience serving a district hospital in rural Taitung County. J Formos Med Assoc. 2021;120(1):422-428. DOI:10.1016/j.jfma.2020.06.007. PMID: 32563581.

28. Feng H, Berk-Krauss J, Feng PW, Stein JA. Comparison of Dermatologist Density Between Urban and Rural Counties in the United States. JAMA Dermatol Chic Ill. 2018;154(11):12651271. DOI:10.1001/jamadermatol.2018.3022. PMID: 30193349.

29. Paudel V. Tele-dermatology in clinical management of suspected cutaneous leishmaniasis in COVID-19 pandemic. Nepal J Dermatol Venereol Leprol. 2020;18(1):91-92. DOI: 10.3126/njdvl. v18i1.31120.

30. Shrestha S, Yadav RS, Baral S, Shrestha DP. Mobile teledermatology in diagnosis and management of two tinea incognito cases at a primary health center of semi-urban Kathmandu. J Chitwan Med Coll. 2018;8(3):69-72. DOI:10.3126/jcmc.v8i3.23755

31. Thind CK, Brooker I, Ormerod AD. Teledermatology: a tool for remote supervision of a general practitioner with special interest in dermatology. Clin Exp Dermatol. 2011;36(5):489-494. DOI:10.1111/j.1365-2230.2011.04073.x. PMID: 21507041.

32. Carrion C, Robles N, Sola-Morales O, Aymerich M, Ruiz Postigo JA. Mobile Health Strategies to Tackle Skin Neglected Tropical Diseases With Recommendations From Innovative Experiences: Systematic Review. JMIR MHealth UHealth. 2020;8(12):e22478-e22478. DOI:10.2196/22478. PMID: 33382382.

33. Velasco J. A Smartphone-Based Skin Disease Classification Using MobileNet CNN. Int J Adv Trends Comput Sci Eng. Published online 2019:2632-2637. DOI:10.30534/ijatcse/2019/116852019.

34. Bartovic J, Padovese V, Pahlman K. Addressing the challenges to skin health of refugees and migrants in the WHO European region. Trop Med Int Health. Published online 2021. DOI:10.1111/ tmi.13552. PMID: 33471432.

35. Khan SS, Padovese V, Maurer TA, et al. A skin disease and needs assessment analysis of the displaced Rohingya population in the Kutupalong refugee camp, Bangladesh. Clin Exp Dermatol. 2020;45(8):1051-1054. DOI:10.1111/ced.14310. PMID: 32460353.

36. Hotez PJ. The rise of neglected tropical diseases in the "new Texas.” PLoS Negl Trop Dis. 2018;12(1):e0005581-e0005581. DOI:10.1371/journal.pntd.0005581. PMID: 29346369.

37. Watchmaker L, Watchmaker J, DeLeon D, Stavert R. Leprosy Diagnosed via Teledermatology in a U. S. Urban Academic Health Center Highlights Potential Benefits and a Pitfall of Existing Telemedicine Services. Telemed J E Health. 2019;25(9):867-869. DOI:10.1089/tmj.2018.0142. PMID: 30207893.

38. CDC - Global Health - Neglected Tropical Diseases. Published March 2, 2021. Accessed March 3, 2021. https://www.cdc.gov/ globalhealth/ntd/index.html

39. John B. Are you ready for General Data Protection Regulation? BMJ. 360:k941-k941. DOI:10.1136/bmj.k941. PMID: 29500167.

40. Brunasso AMG, Massone C. Controversies on WhatsApp for teledermatologic services. Dermatol Ther. 2020;33(6):e14005n/a. DOI:10.1111/dth.14005.

41. Hotez PJ, Velasquez RM, Wolf JE. Neglected Tropical Skin Diseases: Their Global Elimination Through Integrated Mass Drug Administration? JAMA Dermatol Chic Ill. 2014;150(5):481-482. DOI:10.1001/jamadermatol.2013.8759.PMID: 24671756.

42. Mitjà $\mathrm{O}$, Marks M, Bertran L, et al. Integrated Control and Management of Neglected Tropical Skin Diseases. PLoS Negl Trop 
Dis. 2017;11(1):e0005136-e0005136. DOI:10.1371/journal. pntd.0005136.PMID: 28103250.

43. Roberto E, Guadalupe C-L, Guadalupe E-C, Hay R. Mycetoma and the Community Dermatology Program, Mexico. Trans $R$ Soc Trop Med Hyg. Published online 2021. DOI:10.1093/trstmh/ traa199. PMID: 33479763.
44. Rawlings Parker E, Sethi. Chagas Disease: Coming to a Place Near You: Special Topics in Tropical Dermatology. Dermatol Clin. 2011;29(1). DOI: 10.1016/j.det.2010.08.011. PMID: 21095528. 